\title{
O DOENTE ESQUIZOFRÉNICO QUE VIVE NA RUA Tratamento impossível?
}

\author{
António Bento \\ Resumo O sem-abrigo é uma pessoa excluída, que não tem casa e perdeu \\ ou afrouxou os laços com a família e a sociedade. As doenças psiquiátricas, \\ o alcoolismo e a toxicodependência são frequentes. Tendo por base uma \\ experiência de dez anos com os sem-abrigo, nas ruas de Lisboa, o autor descreve \\ e comenta alguns casos. Vivendo na rua, é importante que haja equipas de rua que \\ vão ao seu encontro, estabelecendo uma relação com eles, avaliando os seus casos \\ e propondo soluções.
}

Palavras-chave Sem-abrigo, doenças psiquiátricas, alcoolismo, toxicodependência, equipas de rua.

Um sem-abrigo é uma pessoa que, além de não possuir um local para habitar, perdeu progressivamente os laços com a família, os amigos e a sociedade em geral. Podemos dizer que é um excluído social e, quase sempre, um pobre.

A Comunidade Europeia tem mais de 50 milhões de pobres e 3 milhões de sem-abrigo. Destes, cerca de um terço sofre de doenças mentais.

A esquizofrenia é geralmente considerada como a doença psiquiátrica mais frequente nos sem-abrigo, muitas vezes associada a consumos de álcool ou drogas (Bachrach \& Nadelson, 1988; Cohen \& Crane, 1996; Tsemberis et al., 1993).

O consumo excessivo de álcool é ainda muito frequente, mas os sem-abrigo de hoje estão longe de corresponder à clássica imagem do velho vagabundo alcoólico. Actualmente, o número de mulheres, de jovens, ou mesmo de pessoas com graus académicos elevados ou provenientes de várias classes sociais, tem vindo a aumentar nos países ocidentais.

O interesse científico por estas questões é relativamente recente, embora a literatura e a arte se lhe refiram desde sempre (Almeida, 1994; Amado, 1970; Amalrik, 1977; Aster, 1990; Bashô, 1986; Camões, 1963; Forrester, 1997; Gibran, 1989; Gorki, 1973; Leskov, 1975; London, 1995; Santos et al., 1987). De igual modo, os sem-abrigo sempre tiveram presentes nos sistemas legislativos, embora com outros nomes (mendigos, vagabundos, vadios). A Lei das Sesmarias (século XIV) é a primeira grande lei nesta matéria, mas podemos encontrar outras anteriores, desde o século XII (Fatela, 1989).

Os processos que levam uma pessoa a ser um sem-abrigo são quase sempre complexos e multifactoriais (Costa, 1998), num somatório de perdas que levam à 
rua. A literatura refere dois tipos de causas: as estruturais, como o desemprego, a pobreza, as políticas habitacionais e sociais; e as individuais, onde se situam as doenças físicas e mentais, os consumos de álcool e drogas e as perdas de valores.

Em trabalhos que efectuámos, num albergue (Bento \& Marmeleiro, 1989) e na rua (Bento \& Barreto, 1996), encontrámos um número significativo de psicoses e de esquizofrenias. A co-morbilidade com o álcool e drogas foi elevada, em concordância com a literatura. Só raramente um ou mais dos seguintes factores não estavam presentes: perdas ou rupturas familiares graves, doenças mentais, alcoolismo e toxicodependência.

\section{Equipas de rua}

Os doentes mentais que vivem na rua raramente acorrem aos serviços. Assim, são os serviços que devem ir ter com eles.

Uma equipa de rua deve ser multidisciplinar (psicólogos, assistentes sociais, psiquiatras e outros técnicos), para que os doentes avaliados na rua sejam servidos por programas que contemplem as suas múltiplas necessidades.

Entre a indiferença de nada fazer ou a "limpeza" das ruas (que tem ocorrido em vários países), a melhor solução é, sem dúvida, aquela que começa com uma avaliação técnica in loco.

O trabalho de rua é talvez o mais importante, o mais intenso e o de maior risco. $\mathrm{O}$ que fazer quando um doente esquizofrénico dorme ao frio junto de um contentor de lixo e recusa ajuda? Ou quando somos fisicamente ameaçados? Ou quando alguém nos diz que quer morrer na rua? E se nos oferecem um caroço de azeitona, uma banana ou uma garrafa de vinho? E se nos pedem desesperadamente ajuda? Estes exemplos mostram que é impossível nada fazer e que a partir daqui tudo é possível.

\section{Experiências pessoais}

Ao longo de dez anos de convivência com centenas de doentes mentais sem-abrigo, verificámos evoluções diversas, em relação aos doentes com esquizofrenias. Os casos seguintes exemplificam algumas situações-tipo que ocorreram durante o nosso trabalho (Bento \& Barreto, 1996).

\section{A morte}

A morte é um desfecho comum para os sem-abrigo. Sem família, morrem silenciosamente, ignorados por quase todos. Numa semana de frio em que houve três mortes, verificámos que os velórios não tinham ninguém. 
Em 1994, encontramos João, 72 anos, a viver há cerca de um ano na rua. Sem família, diz ter sido "casado com uma ministra". Ao fim de um mês conseguimos que esteja a dormir num quarto. Três meses depois volta a dormir na rua, agravando-se o seu estado de saúde. É internado em hospital geral, devido a expectoração sanguinolenta e febre. Apesar da pneumopatia, da diabetes e de ainda estar sub-febril, tem alta disciplinar, devido ao seu "mau comportamento" e é entregue aos serviços sociais. Morre no dia seguinte ao da alta, estando ainda no hospital.

\section{A lembrança dos laços perdidos}

É frequente encontrar doentes esquizofrénicos a viver em locais significativos, em termos de laços antigos, já extintos.

António vivia num hospital psiquiátrico e passava o fim-de-semana em casa da família. Um dia, há cerca de 30 anos, chegou a casa e não encontrou ninguém. Desde então vive na rua, junto à antiga casa familiar. Os vizinhos ajudam-no e tem copo próprio numa leitaria da rua. Ele diz que já não é "ele": "Ele vivia ali", diz, referindo-se a si próprio e apontando a sua antiga casa.

Junto a terminais vêem-se doentes que provêm de terras servidas por esses transportes (por exemplo, Santa Apolónia, para os sem-abrigo do Norte e Centro ou Terreiro do Paço, para os do Alentejo e Algarve). Noutros casos, dormem à porta de antigos locais de trabalho.

\section{A Perda da identidade}

Alguns sem-abrigo estão de tal forma degradados que já não sabem quem são, nem o seu próprio nome.

João, ou Jean, quase não fala, dizendo apenas algumas palavras em francês. Ninguém sabe quem é, qual a sua nacionalidade ou de onde veio, mesmo depois de ter aparecido na televisão. Vive há alguns anos na rua, sendo alimentado por umas senhoras que lhe põem comida no chão, em pratos de plástico, de onde come à mão.

Tiago come dos caixotes do lixo e à noite dorme numa avenida, num saco preto, com grave risco de ser esmagado por automóveis. Quase não fala e diz que está "bem". Conseguimos ouvi-lo dizer o nome da sua terra. Depois, através da polícia e de outros serviços, ficámos a saber que não tem família, excepto a mãe, que está internada há muitos anos num hospital psiquiátrico. No dia em que lhe revelamos o seu nome parece admirado: "Pois é! Ele era o Tiago!"

\section{A nudez e a agressividade como vias de acesso ao tratamento}

Tal como noutros países, apenas a nudez ou a agressividade permitem a actuação das polícias e, deste modo, a condução a serviços psiquiátricos.

Emílio, com cerca de 30 anos, passa horas de pé, imóvel, num passeio. 
Algumas pessoas tentam dar-lhe dinheiro, mas ele nem os olhos mexe, havendo algumas moedas no chão. Está nu, mas tem ainda um cobertor a tapar os genitais e parte do corpo. Quase ao lado, os polícias de uma esquadra aguardam que a nudez seja total para poderem intervir e conduzi-lo a um hospital psiquiátrico, onde já esteve internado.

Andrade vive há muitos anos na rua, dormindo sentado no passeio. Um dia uma senhora queixa-se de ter sido esbofeteada por ele. Conduzido pela polícia à urgência psiquiátrica, fica internado, com o diagnóstico de esquizofrenia, verificando-se que teve outros internamentos psiquiátricos.

\section{Trajectórias múltiplas}

Seguir as múltiplas trajectórias que os sem-abrigo podem ter é um labirinto onde nos perdemos com facilidade: rua, albergues, serviços de psiquiatria, serviços sociais, trabalhos precários, ajudas privadas e de associações, mudanças de terra, tudo pode acontecer.

Paulo: "Andei pela Costa, dormia por lá, os pescadores eram muito simpáticos, mas era muito frio à noite, na praia!"

Octávio, 24 anos, teve alta em 1997 de um serviço de psiquiatria, esteve num hospital de dia, em tratamento noutro serviço de psiquiatria, na rua, num albergue, a trabalhar e, quando se preparava para entrar num atelier ocupacional, voltou a ter uma descompensação psicótica, ficando internado. Já melhorado, ao falar connosco reconhece-nos, mas não nos identifica. Vai tentando: "Vocêé..." e vai citando nomes de psiquiatras, psicólogos, assistentes sociais, instituições...

\section{Rua - hospital - comunidade religiosa}

Nos casos mais bem sucedidos, há geralmente uma participação muito activa de múltiplas pessoas, técnicos e instituições.

Francisca, 72 anos, Teresa, 69 anos, e Estevão, 62 anos, têm em comum muitos anos de vida de rua, ausência de famílias e esquizofrenias. Participámos em várias fases de um longo processo, desde o contacto na rua, durante anos, até à ida para uma comunidade religiosa, passando pelo internamento psiquiátrico. Se os três estão actualmente equilibrados e mostram satisfação com a sua actual situação, em todos houve acidentes de percurso: após a alta psiquiátrica as mulheres tiveram uma reactivação dos sintomas psicóticos (delírios, alucinações), Francisca esteve hospitalizada por doença febril, Teresa sofreu fractura de um punho e Estevão voltou para a rua, durante algumas semanas, com agravamento da úlcera de perna e necrose de tecidos. 


\section{O regresso à família e à terra natal}

De entre as evoluções mais favoráveis, esta é a mais rara.

Mário, 58 anos, primeiro contacto na rua em 1988. Dizia que se chamava "Hitler" e que era o homem mais rico do mundo, estando à espera de um avião ("Vou formar um mundo novo!"), tão gigantesco que não cabia no jardim onde estava. Dormindo à porta de uma igreja, apresentava excrementos de pombos nas longas barbas e cabelos. Coerentemente com os conteúdos delirantes, não aceitava ajudas, sorrindo: "Não preciso, obrigado. Tenho tudo!" Dez anos depois já fala pouco e quase não tem produção delirante. Aintervenção de uma irmã, da polícia, de serviços sociais, e o internamento psiquiátrico durante meses, permitiram criar as condições para que a família o pudesse receber no seu Alentejo natal.

\section{Da rua à integração profissional}

Há casos, excepcionais, em que os sem-abrigo psicóticos, com acompanhamento técnico, conseguem reorganizar-se e ter uma vida normal.

António, 39 anos, tem o primeiro contacto connosco na rua em 1997. Cabelos compridos, muito sujo, vai comendo dos caixotes do lixo e do que umas senhoras lhe dão. Ao contrário do esperado, o diálogo é fácil, aceita ir a uma urgência psiquiátrica e, posteriormente, às consultas de psiquiatria. Apoiado em alojamento e fazendo terapêutica neuroléptica, entra para atelier ocupacional e, pouco tempo depois, por sua iniciativa, procura e arranja emprego, na indústria hoteleira.

\section{O doente esquizofrénico na rua: caso impossível?}

Os casos mais frequentes são aqueles em que os doentes esquizofrénicos vivem na rua, em condições de degradação progressiva, durante anos, havendo um sentimento de impotência por parte de quem os quer ajudar. Nalguns casos é desencadeado o processo judicial, longo e por vezes penoso para os próprios técnicos, sendo contudo o único que actualmente permite, legalmente, o acesso aos serviços de saúde dos doentes muito incapacitados e sem juízo crítico para a sua situação.

\section{Tratamento e reabilitação}

O tratamento destes doentes psicóticos permite quase sempre uma remissão dos sintomas, pelo menos parcial, abrindo perspectivas para uma vida independente e com algum grau de adaptação social e ocupacional. Uma das tarefas mais difíceis é precisamente conseguir que os doentes sejam tratados.

À falta de aderência dos doentes esquizofrénicos aos tratamentos, acresce a 
inexistência de legislação que permita o tratamento de doentes sem-abrigo incapacitados pela doença e a escassez de serviços e recursos.

A interacção social dos doentes esquizofrénicos sem-abrigo é muito difícil e cheia de perigos. A ambivalência está quase sempre presente: querem comunicar, mas também não querem, porque têm medo e desconfiam dos outros.

Na rua é virtualmente impossível tratar um doente esquizofrénico. Se as múltiplas barreiras que dificultam o acesso aos serviços forem transpostas, verifica-se que, tal como em meio familiar, nas instituições os doentes suportam mal níveis elevados de criticismo, hostilidade ou envolvimento emocional excessivo. Muita estimulação e emoções expressas em grau elevado são sentidas como ameaçadoras e podem levar a recaídas.

O tratamento psicofarmacológico é essencial e quase sempre indispensável. Os neurolépticos são os mais utilizados, mas pode haver indicação para outros medicamentos, em associação: carbamazepina, para potenciação dos neurolépticos, em doentes agressivos; benzodiazepinas e outros ansiolíticos; lítio, em doentes com sintomas afectivos; propanolol, em doentes com irritabilidade, organicidade ou em casos de resistência a outros fármacos. O uso de antidepressivos é mais controverso, mas podem estar indicados em doentes deprimidos.

O tratamento psicoterapêutico intensivo está contra-indicado, sendo aconselhável uma abordagem psico-educacional, que enfatize o apoio, a educação e a aquisição de aptidões.

Raramente os doentes esquizofrénicos beneficiam com psicoterapias de insight, em que as interpretações conduzem por vezes a importantes regressões e descompensações, sem qualquer ganho terapêutico. Pelo contrário, a presença do terapeuta, na medida certa, aceitando os delírios e os comportamentos psicóticos, sem os confirmar nem contrariar, corrigindo aspectos pragmáticos, mas não se impondo ao doente, é a melhor atitude terapêutica.

É importante que, após a alta hospitalar, haja apoio intensivo dos serviços, pois é esse o período mais crítico. A institucionalização em albergues ou alojamento longe dos locais a que os doentes se sintam ligados podem ser inapropriados.

\section{Algumas propostas}

Numa primeira fase, seria vital que fossem tratados os casos mais graves, procurando salvar vidas, no que quase todos estariam de acordo, evitando-se as polémicas estéreis e desgastadoras que ocorreram noutros países.

As intervenções em doentes que ainda conservam algumas capacidades e meios de sobrevivência, poderiam ficar para uma segunda fase, dando tempo para que os problemas dos doentes mentais que vivem na rua fossem publicamente discutidos.

A urgência máxima deve ser para os doentes em risco de vida ou em processo de grave ou irrecuperável perda de capacidades psíquicas. 
À semelhança do que já ocorreu em outros países, como o Reino Unido ou os Estados Unidos da América, é imprescindível a existência de legislação que permita uma actuação rápida e eficaz em doentes que já não têm capacidade de avaliar situações e tomar decisões.

A lei n. ${ }^{\circ} 365 / 76$ limitou-se a abolir a repressão à mendicidade. A nova Lei de Saúde Mental (lei n. ${ }^{\circ} 36 / 98$, de 24 de Julho) já permite o acesso dos doentes mentais incapazes de decidir acerca de si próprios aos cuidados de saúde.

Os programas deverão contemplar os seguintes pontos, sequencialmente:

- identificação dos casos de risco de morte ou grave risco para a saúde;

- equipas técnicas de rua, móveis, flexíveis e multidisciplinares (psiquiatras, psicólogos, assistentes sociais, etc.), para avaliação individual, com designação de gestores para cada caso;

- activação dos meios que promovam o acesso ao tratamento em instituição de saúde mental, sempre que possível com a participação do próprio doente, mas sem o seu consentimento, se não for possível, por incapacidade deste;

- acompanhamento jurídico, tendo em vista a protecção do doente, promovendo o seu direito à saúde, aos tratamentos e à cidadania;

- programas de reabilitação psiquiátrica e social, sempre que possível junto da família ou de locais significativos para o doente.

É surpreendente, mesmo para quem trabalha há muito tempo com sem-abrigo psicóticos, mas há casos com uma sinergia feliz de pessoas, técnicos, instituições e doentes, sendo possível extraordinários progressos, clínicos, sociais e pessoais. A experiência mostra-nos que o abandono, a miséria e a morte não precisam de ser uma fatalidade para os sem-abrigo e que é possível fazer um bom trabalho em benefício destes doentes.

\section{Referências}

Almeida, M. (1994). Memórias de um sargento de milícias. Lisboa: Editores Reunidos. Amado, J. (1970). Capitães da areia. Lisboa: Publicações Europa-América.

Amalrik, G. (1977). Memórias de infância e de miséria. Lisboa: Perspectivas e Realidades.

Aster, P. (1990). O Palácio da lua. Lisboa: Editorial Presença.

Bachrach, L., \& Nadelson, C. (1988). Treating chronically mentally ill women. EUA:

American Psychiatric Press.

Bashô (1986). O gosto solitário do orvalho. Lisboa: Assírio e Alvim.

Bento, A., \& Marmeleiro, C. (1989). Doentes mentais sem casa (homeless) em Lisboa: I doentes mentais que dormem na rua. II — doentes mentais num albergue de Lisboa. Revista do Hospital Júlio de Matos, 2, 11-21.

Bento, P., \& Barreto, A. (1996). Os sem-abrigo nas ruas de Lisboa. Lisboa: Santa Casa da Misericórdia de Lisboa. 
Camões, L. (1963). Os lusíadas. Porto: Livraria Civilização Editora.

Cohen, C., \& Crane (1996). Homelessness and mental health. Londres: Cambridge University Press.

Costa, B. (1998). Exclusões sociais. Lisboa: Gradiva.

Fatela, J. (1989). O sangue e a rua: Elementos para uma antropologia da violência em Portugal (1926-1946). Lisboa: Publicações Dom Quixote.

Forrester, V. (1997). O horror económico. Lisboa: Terramar.

Gibran, K. (1989). O vagabundo. Braga: Editorial A. O.

Gorki, M. (1973). O vagabundo filósofo. Porto: Livraria Civilização.

Léskov, N. (1975). O vagabundo encantado. Lisboa: Editorial Futura.

London, J. (1995). O vagabundo e outras histórias. Lisboa: Edições Dinossauro.

Santos, P., Rodrigues, T., \& Nogueira, M. (1987). Lisboa setecentista vista por estrangeiros. Lisboa: Livros Horizonte.

Tsemberis, S., Cohen, N., \& Jones, R. (1993). Intensive treatment of the homeless mentally ill. EUA: Americam Psychiatric Press.

Homeless schizophrenic: an impossible treatment? (abstract) Homeless is an excluded person, who lost or weekened the ties with the family and the society. Psychiatric diseases, alcoholism and drug dependence occurs frequently. Based in his experience on working with homeless for ten years, on the streets of Lisbon, the author describes and comments some cases. Living on the streets, it is important to have multidisciplinar outreach teams to meet homeless, having a relationship with them, evaluating their cases, and purposing solutions. 